\title{
SYNTHESIS
}

Synthesis

ISSN: 0328-1205

ISSN: 1851-779X

revistasynthesis@gmail.com

Universidad Nacional de La Plata

Argentina

\section{Consideraciones sobre \#\#\#\# a partir de Anábasis de Jenofonte}

\author{
Díaz Roulier, Gonzalo Néstor \\ Consideraciones sobre \#\#\#\# a partir de Anábasis de Jenofonte \\ Synthesis, vol. 26, núm. 2, 2019 \\ Universidad Nacional de La Plata, Argentina \\ Disponible en: http://www.redalyc.org/articulo.oa?id=84662943005 \\ DOI: https://doi.org/10.24215/1851779Xe062
}

Esta obra está bajo una Licencia Creative Commons Atribución-NoComercial-Compartirlgual 4.0 Internacional. 
Artículos

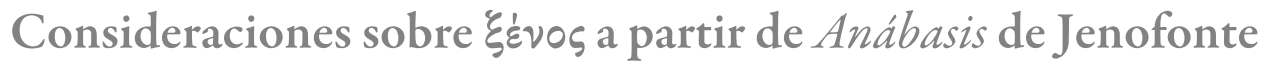

Considerations about 乡̇ंvos Based on Xenophon's Anabasis

Gonzalo Néstor Díaz Roulier

DOI: https://doi.org/10.24215/1851779Xe062
Redalyc: http://www.redalyc.org/articulo.oa?id=84662943005

Universidad Nacional de Mar del Plata, Argentina

gdiazroulier@gmail.com

(DD http://orcid.org/0000-0002-7531-0105

Recepción: 24 Septiembre 2019

Aprobación: 25 Noviembre 2019

\section{Resumen:}

Entre las raíces de origen griego que se mantienen en el español actual se halla $\xi \dot{\varepsilon} v o \varsigma$ con el sentido 'extranjero'. Sin embargo, en el griego clásico esta palabra portaba un gran espectro de significados adicionales vinculados a la acción hospitalaria. A través de una serie de pasajes seleccionados de la Anábasis de Jenofonte se muestran varios de estos otros sentidos de xénos en el griego ático del

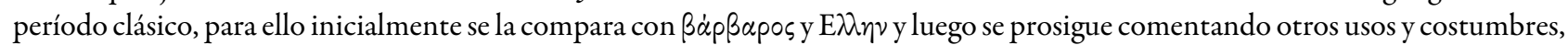
así como su contexto.

Palabras ClaVe: Filología, Jenofonte, Anábasis, Bárbaro, Extranjero, Hospitalidad.

\section{Abstract:}

Among the Greek roots that remains in the present Spanish there is $\xi \dot{\varepsilon} v \circ \varsigma$ with the meaning 'foreinger'. However, in the classical Greek this word has a large spectrum of additionals meanings attached to the hospitality action. Through a serie of selected pasajes from Xenphon's Anabasis several of these others senses are showed in the classical attic Greek, with that porpose initially it is compared with $\beta \dot{\alpha} p \beta \alpha \rho \circ \varsigma$ and $E \lambda_{\eta} \nu$ and then others usages and customs and its context are commented.

KEYWORDs: Philology, Xenophon, Anabasis, Barbarian, Foreinger, Hospitality.

\section{INTRODUCCIÓN}

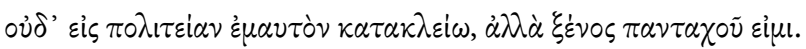

Ni me encierro en ninguna ciudadanía, sino $\xi \dot{\varepsilon} \nu \circ \varsigma$ soy en todos lados.

X.Mem.II.1.13

La memoria de Jenofonte que sirve de epígrafe pertenece a un diálogo entre Sócrates y Aristipo de Cirene, quien pronuncia la frase. Usualmente allí '่̧vvos es traducido como 'extranjero' y Sócrates señala que eso es

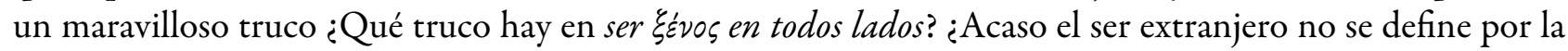
circunstancia del hablante?

Esta investigación presenta un recorrido de fragmentos de Anábasis de Jenofonte que incluyen el término $\xi \dot{\varepsilon} v o \varsigma$, mostrando que el sentido 'extranjero' no es pertinente o insuficiente en muchos casos. Los fragmentos fueron escogidos tras realizar un rastreo de las raíces de estos términos en el texto. No se presentan según su orden su aparición, sino que su orden responde a una mejor exposición filológica, pues se comentan prácticas sociales implicadas en la costumbre de $\xi \varepsilon v i \alpha$ 'hospitalidad'.

\section{Comparación de TÉrminos}

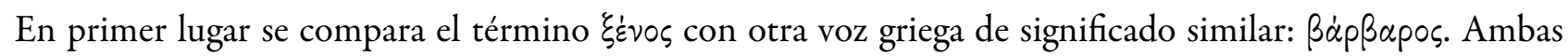
comparten el sentido 'extranjero', aunque $\xi$ غ่vos presenta una importante gama de significados adicionales de 
la que $\beta \dot{\alpha} p \beta a p o s$ carece. Iniciemos pues el recorrido de significados por el siguiente pasaje, previo a la batalla de Cunaxa:

\section{1. - X.An.I.8.1 - Bárbaros y helenos}

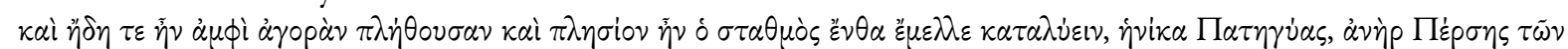

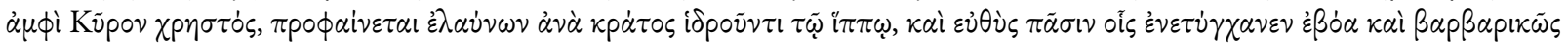

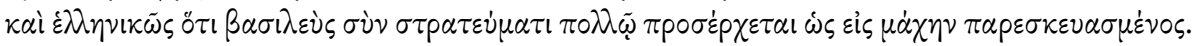

Y era ya el momento en que está lleno el mercado y cerca estaba el lugar de descanso donde tenía intención de parar , cuando Pategias, bravo varón persa cercano a Ciro, apareció montando a galope tendido con el caballo sudando, y sin dilación a todos los que encontraba gritaba tanto en bárbaro como en griego que el rey venía con mucho ejército, como preparándose para la batalla. ${ }^{1}$

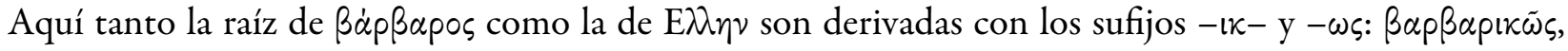
$\varepsilon \lambda \lambda_{\eta} \nu \kappa \omega \tilde{\omega}$. Ambos adverbios son regidos por $\beta \circ \alpha \omega$ 'gritar, clamar' e indican el idioma empleado: Pategias gritó tanto en bárbaro -en persa- como en griego.

El lenguaje, como es sabido, es lo que diferencia al $\beta \dot{\alpha} p \beta \alpha \rho o s$ del E $\lambda \eta \nu$; ambos términos se determinan mutuamente: $\beta \dot{\alpha} p \beta \alpha \rho \rho_{\text {es }}$ era para un griego aquel extranjero que hablaba un idioma extraño, que no entendía y que le parecía tartamudeante. La palabra es de formación onomatopéyica parecida al sánscrito barbara ("que tartamudea"), el bar-bar sumerio (“extranjero"), al lat. balbus ("tartamudo"), o en español a balbucear, farfullar. Según Chantraine (1968, pp. 764-765), este sentido sobre el lenguaje se aprecia especialmente en compuestos como $\beta \alpha \rho \beta \alpha \rho o ́ \phi \omega v o s$ o $\beta \alpha \rho \beta \alpha \rho o ́ \gamma \lambda \omega \sigma \sigma o s$.

El segundo fragmento permite ver lo esencial de $\beta \dot{\alpha} \rho \beta \alpha \rho o s$, pues aparece como superlativo calificando al extraño pueblo de los mosinecos. Este uso muestra que lo que más distingue al bárbaro es lo incomprensible. Dice el texto:

\section{2. - X.An.V.4.34 - Los más bárbaros}

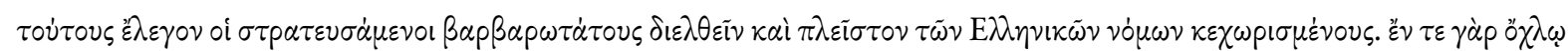

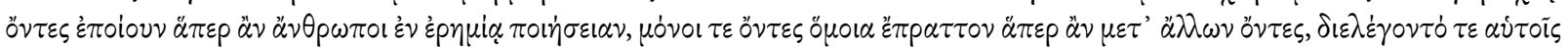

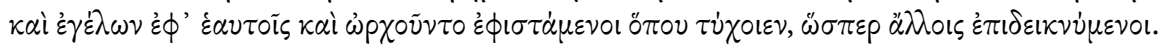

A estos los que marcharon con el ejército consideraban los más bárbaros entre los que habían marchado y más diferentes de las costumbres helénicas. Pues estando en multitud hacían las cosas que precisamente los hombres podrían hacer en soledad, y estando solos llevaban a cabo las mismas cosas que si estuvieran entre otros: hablaban para sí y reían de sí mismos y bailaban deteniéndose donde casualmente se encontraban, como exhibiéndose para otros.

En el tercer fragmento seleccionado aparece la raíz de $\xi^{\varepsilon} v o \varsigma$. Allí los adjetivos sustantivados en neutro

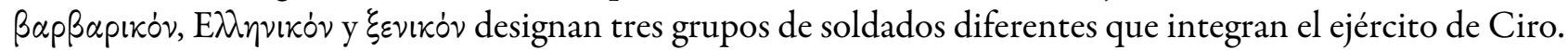
La sustantivación neutra de un derivado con - $\downarrow$ - crea un sentido de grupo, de sustantivo colectivo.

A lo largo del texto se advierte que los cuerpos del ejército se dividen por armas y etnias, pero no

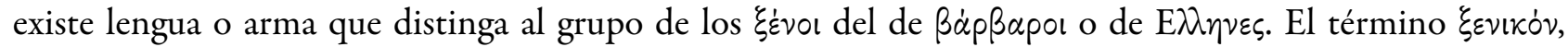
advierte Trundle (1996, p. 56), adquirió uso y aceptación durante el siglo IV a. C. para referir a mercenarios contratados por los atenienses durante la Guerra de Corinto (395-387 a. C.). En Anábasis el término es usado solo dos veces (I.2.1, II.5.22), pero en Helénicas es más frecuente. Dice el fragmento:

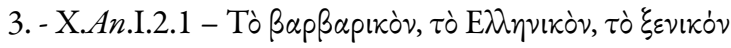

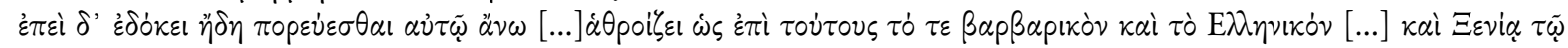

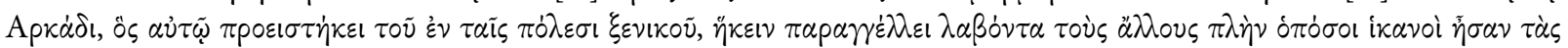
$\dot{\alpha} \kappa p \circ \pi \dot{\lambda} \lambda \varepsilon \iota \varsigma \phi v \lambda \dot{\alpha} \tau \tau \varepsilon เ v$.

Y cuando ya le parecía marchar tierra adentro [...] reúne como contra estos a las tropas bárbaras y a las helenas [...] y a Jenias, el arcadio, que había puesto consigo al frente de las tropas mercenarias en las ciudades, manda estar presente habiendo alistado a las otras, excepto cuantas eran suficientes para guardar las acrópolis. ${ }^{2}$ 
Así pues, hay un contingente de bárbaros, otro de helenos y otro de 'extranjeros' o de 'mercenarios'. Los

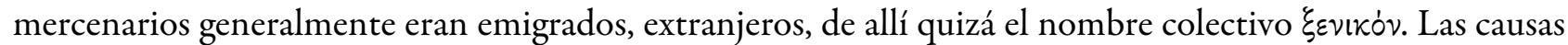
de emigración eran múltiples: exceso de población, guerra, destrucción de ciudades, expatriaciones, etc. La mayoría de los mercenarios eran del Peloponeso, de Arcadia y de Tesalia, solo tras la Guerra del Peloponeso se registran mercenarios atenienses. ${ }^{3}$

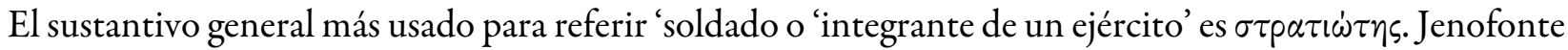
indica que muchos de ellos recibían $\mu \iota \sigma \theta o ́ s$. El $\mu \iota \sigma \theta$ ós es un pago regular -característica del ser mercenario sobre la que más adelante se vuelve-, su regularidad es dada en relación a la frecuencia de las lunas ( $\mu \tilde{\eta} v a \imath$ ), por ejemplo:

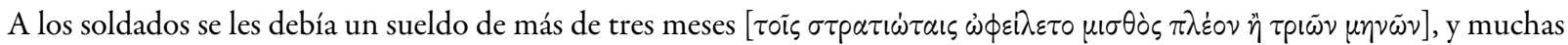
veces iban a la tienda de Ciro y lo reclamaban. Él los distraía dándoles esperanzas, y era evidente que estaba disgustado, pues no era propio del carácter de Ciro tener y no pagar. En Caístro, Epiaxa, la mujer de Siénesis, el rey de los cilicios, se unió a Ciro, a quien dio, según se contaba, mucho dinero. Así pues, Ciro pagó entonces al ejército el sueldo de cuatro meses (X.An.I.2.11-12, trad. Varias, 1999).

Por otro lado, en las partes omitidas del tercer fragmento se especifican algunas de las tropas del grupo

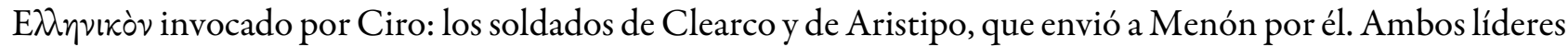

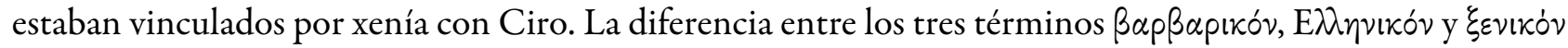
parece señalar entonces los tres orígenes del ejército y presumiblemente se diferencia así al grupo aristocrático heleno del de mercenarios $\mu i \sigma \theta 10 \varsigma$, contratados por Ciro.

En el cuarto fragmento el epíteto de Zeus, $\xi \dot{\varepsilon} v 10 \varsigma$, presenta la hospitalidad como un hecho social religiosamente amparado, como una institución donde los lazos hospitalarios llegan a tener un carácter sacro. El pasaje es un extracto de la asamblea posterior a la muerte de Clearco, general que fue asesinado a traición durante una negociación. En la asamblea los griegos discuten su situación actual: qué hacer, cómo continuar

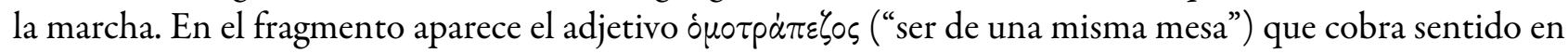
el contexto de los banquetes por xenía, pues el vínculo hospitalario se celebraba compartiendo una comida:

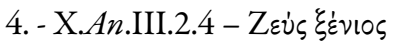

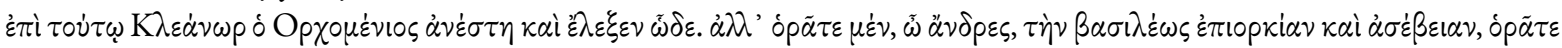

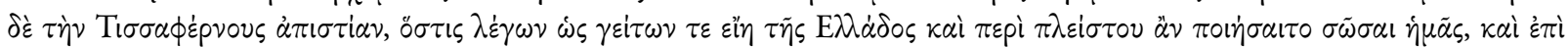

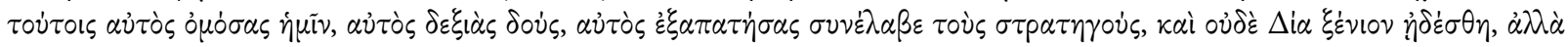

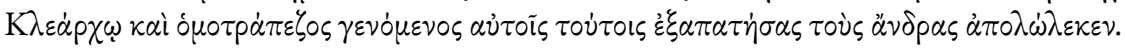

Por esto, Cleanor, el Orcomenio, se puso de pie y dijo así: ¡Otra cosa, oh hombres! ¡Vean la perjura y la impiedad del rey! ¡Y vean la deslealtad de Tisfarnes! Que diciendo que era vecino de los helenos y que haría todo para salvarnos, y mientras nos juraba por estas cosas dando la mano derecha, engañando reunió a los estrategos iy ni a Zeus, protector de huéspedes, respetó! Sino que también con esas mismas cuando llegó a ser compañero de mesa con Clearco, engañando ha matado a los hombres.

En el cotexto Cleanor sigue como orador a Quirísofo, general espartano, y ż $\pi$ i $\tau o \nu ่ \tau \omega$ refiere a sus últimas

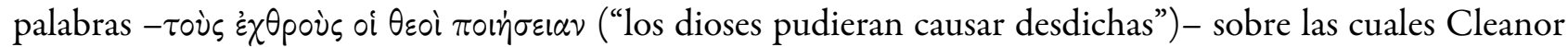
construye el núcleo de su discurso: si alguien debe temer a los dioses son los persas, dado lo impío del acto cometido por Tisafernes al romper un pacto guardado por Zeus $\xi \dot{\varepsilon} v ı \varsigma$.

Los fragmentos siguientes presentan distintos valores de xenía, mostrando su consideración política y distintas concreciones a nivel aristocrático y plebeyo. Como institución, tiene un origen remoto, de cuando la hostilidad entre pueblos vecinos era habitual y no existía posibilidad de alianzas entre comunidades. Los individuos podían conseguir auxilio de dos formas: una, el parentesco (el matrimonio); otra, la amistad por hospitalidad. El ser amigo y huésped implicaba una relación determinada, evocadora de derechos y deberes (Finley, 1954, pp. 50-54).

Fustel de Coulanges (1996, pp. 129-134) al describir la religión doméstica en general, y en particular la incorporación de nuevos miembros a una familia, resalta como el acto de compartir una comida preparada 
sobre un mismo altar creaba un lazo indisoluble que solo cesaba con la muerte. Este principio, indica, era también constitutivo para la hospitalidad: a quien había logrado tocar el altar no se consideraba extranjero.

Cuando un individuo llegaba a ser xénos poseía un eficaz sustituto del parentesco: accedía a un protector, a un representante, a un refugio, a un almacén al que acudir al viajar y a una reserva de hombres y armas si debía combatir. De allí que la frase de Aristipo usada como epígrafe fuese un truco para Sócrates.

Sin embargo, según Iriarte (2007, p. 198), la recepción de un extranjero era un deber religioso variable, dependía de las posibilidades económicas y de la generosidad del receptor. Señala que Gauthier, en Symbola. Les étrangers et la justice dans les cités grecques, distingue dos grados de hospitalidad: uno, el simple amparo que todo $\pi \alpha \tau \dot{\eta} \rho^{4}$ debía ofrecer; otro, donde la hospitalidad llegaba a ser una alianza político-militar entre aristócratas.

El quinto fragmento presenta dos sentidos de $\xi \dot{\varepsilon} v o s$ en una misma oración. Por un lado, como vínculo entre aristócratas, pues Aristipo ${ }^{5}$ y Ciro lo son; por otro, el uso de xénos como eufemismo de 'mercenario', cercano al uso comentado de $\tau \dot{\text { ó } \xi \varepsilon v i k o ́ v: ~}$

\section{5. - X.An.I.1.10 - Diferencias I}

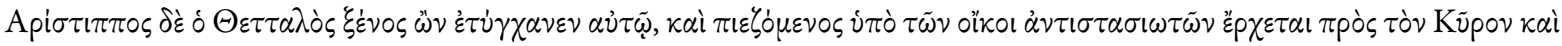

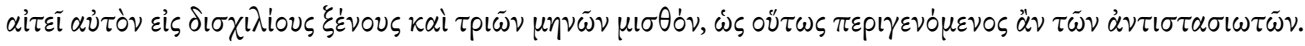

Aristipo, el Tesalo, teniendo justamente vínculo de hospitalidad con él, y estando apremiado por rivales políticos en su casa, va ante Ciro y le pide hasta dos mil mercenarios y su paga de tres lunas, porque así habría de poder ser superior a sus enemigos.

El aprovechamiento del estatus de xénos por Aristipo muestra una alianza entre $\gamma^{\varepsilon} v o s$, una xenía aristocrática, mientras que la mención de la paga marca la diferente naturaleza de la relación con esos otros xénos.

En este punto debe tenerse presente que en la Antigüedad el trabajar para otro regularmente, recibiendo $\mu \iota \sigma \theta \grave{\partial} \varsigma$, no era considerado honorable para un hombre libre, constituía una práctica contraria a principios como la $\dot{\varepsilon} \lambda \varepsilon v \theta \varepsilon p i \alpha$ ("libertad") y la $\alpha \dot{\tau} \tau \dot{\alpha} p \kappa \varepsilon ı \alpha$ ("autarquía”) (Trundel, p. 63). Este hecho provoca que $\sigma \tau p \alpha \tau i \omega \dot{\tau} \eta \varsigma$, el término general para soldado, es decir, soldado-ciudadano, no fuese enteramente adecuado para designar al mercenario sobre el que existía una mala consideración, razón por la que se lo nombra con eufemismos.

Los eufemismos suelen tener vida corta, pues aquellos nuevos términos que intentan moderar con su designación a realidades socialmente mal vistas pronto adquieren el valor negativo del término al que reemplazan, salvo que haya un cambio cultural simultáneo. Este hecho, se observa en la variedad de palabras con el sentido de 'mercenario'. Por ejemplo, Trundle (1996, pp. 53-58) señala que un término primitivo para designarlo fue $\delta \circ \operatorname{pú} \phi o p o s^{6}$ ("lancero"), otro fue $\varepsilon \pi i$ ixoupos (“ayudante, asistente”) (en Homero: "aliado"). Este último término, por ejemplo, se encuentra ya en el siglo VII a. C. en los versos Arquíloco "Seré llamado

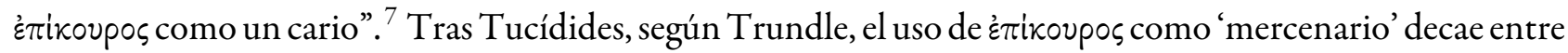
los historiadores. Así, en Anábasis, se encuentra pocas veces la raíz ${ }^{8}$ y ninguna con el sentido 'mercenario'. En Helénicas solo una vez es usada como 'mercenario' (Hel.VIII.1.23) y en toda otra ocasión significa 'socorro', 'asistencia' (Hel.IV.6.3, 83, VI.8.3, 5.40, 47, VII.4.6); en cambio, el término $\mu \iota \sigma \theta$ ó opos 'mercenario' es usado muchas veces. ${ }^{9}$

Este valor negativo se encuentra en Anábasis: se utiliza $\mu \sigma \theta$ ó $\phi \circ o$ para nombrar a desertores y enemigos (I.4.3, IV.3.4, 4.18, VII.8.15), e incluso se llama xúpeı૦ -nombrándoselos por su empleador-a los soldados de Ciro que huyeron tras su muerte:

Y no creáis, por cierto, que valéis menos porque los de Ciro [ desertado. Pues estos son peores incluso que los derrotados por nosotros. (X.An.III.2.17, trad. Varias, 1999)

Pero, cuando Jenofonte nombra a sus compañeros prefiere llamarlos soldados, hoplitas o $\xi \dot{\varepsilon} v o$, usando una designación que modera la mala consideración sobre su actividad, pues no es posible que cada uno de los 
griegos que pelearon en Cunaxa - unos 13000- hayan sido realmente 'huéspedes-invitados' de Ciro. E incluso en VI.4.8 aleja la idea del pago regular de las causas de su $\mu \iota \theta_{\circ} \phi \circ \rho \dot{\alpha} \nu$ ("servicio mercenario"), presentándolo motivado por un deseo de aventura o por la ảpetí de Ciro:

Efectivamente la mayoría de los soldados [oi $\pi \lambda \varepsilon \tilde{\varepsilon} \sigma \tau 0 \iota \tau \tilde{\omega} \nu \sigma \tau p \alpha \tau \iota \omega \tau \tilde{\omega} \nu$ ] se habían hecho a la mar para este servicio mercenario [ $\mu \sigma \theta \circ \phi \circ \rho \dot{\alpha} \nu]$, no por falta de medios de vida sino por haber oído hablar de la excelencia de Ciro; unos llevando hasta sus hombres; otros, incluso, gastando dinero suplementario, y otros distintos de éstos, tras escaparse de casa de sus padres y sus madres; otros llegaron a abandonar a sus hijos a fin de regresar después de haber adquirido dinero para aquellos, pues oían que los demás hombres que estaban con Ciro hacían muchos y buenos negocios. Siendo tales los soldados, ansiaban llegar a Grecia sanos y salvos. (X.An.VI.4.8, trad. Varias, 1999)

Otra evidencia de este uso particular la señala Trundle al indicar que cuando Diodoro de Sicilia historió la expedición -varios siglos después- usó casi exclusivamente $\mu \sigma \sigma \theta \dot{\phi}$ opos donde Jenofonte dice $\xi \dot{\varepsilon} v o \varsigma$ (Diod. XIV.19.3), y cuando usa $\xi \dot{\varepsilon} v \circ$ s aclara que esos hombres eran pagos (Diod. XVI.28.2). ${ }^{10}$

Los fragmentos sexto y octavo presentan banquetes celebrados por xenía y muestran que el invitar y recibir al otro $\varepsilon \pi i \grave{\imath} \dot{\alpha} \xi \dot{\varepsilon} \nu 1 \alpha$ no solo significaba invitarlo a compartir comida, sino también compartir un tiempo de negociación bajo condición de xenía, constituyendo una práctica diplomática ritualizada. ${ }^{11}$ Dice el sexto fragmento seleccionado:

\section{6. - X.An.VII.3.22 - El banquete de Seutes I}

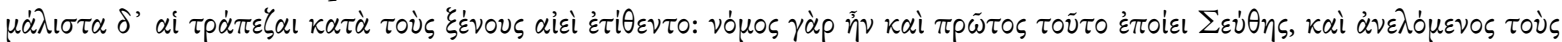

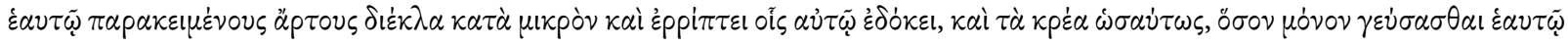
$\kappa \alpha \tau \alpha \lambda \iota \pi \dot{\omega} \nu$.

Y especialmente siempre las mesas eran colocadas ante los huéspedes, pues era costumbre, y primero Seutes, habiendo agarrado para sí los panes que estaban cerca, hacía esto: en dos pequeños pedazos los partía y lanzaba a los que aprobaba con él, también así a las carnes, habiendo dejado para él solo lo suficiente para degustar.

Aquí 乡́ंvovs refiere a varios seres, lo que dificulta su traducción. El ejército se halla en Tracia, sus líderes han sido invitados a un banquete por el rey Seutes, que ha contratado al ejército. Por un lado, la acepción 'extranjeros' parece correcta ya que los griegos lo son, pero por otro excluye a los otros tracios presentes; el significado 'mercenarios' parece adecuado (la paga es incluso discutida en asamblea), pero deja de lado que hay un ritual de unión durante la comida del que también participan embajadores de otros reinos. En consecuencia, he optado por 'huéspedes'.

Antes y después de la comida, varios huéspedes ofrecen dones al rey para obtener su favor. Jenofonte al parecer no esperaba este tipo de celebración: solo tenía un esclavo y estaba avergonzado de no tener qué regalar, en consecuencia se ofrece a sí mismo. Lo mismo ocurre a otros griegos, por ejemplo, un tal Gnesipo, ateniense, menciona que una antigua y muy hermosa costumbre era que los que tenían obsequiaran al rey para honrarle y que, en cambio, el rey obsequiara a los que no tenían, para así luego retribuir el regalo (VII.3.28). 12 Teniendo en cuenta que en el relato una de las principales motivaciones del ejército es el ansia de fortuna, puede que la propuesta de Gnesipo luzca como una avivada, pero ha de considerarse que el intercambio de regalos era un acto casi obligado para sellar acuerdos. Comenta Finley al respecto en La Grecia antigua (1984, p. 269):

Esencialmente el intercambio de regalos era, por lo regular, una acción bilateral, no unilateral. Aunque tenía la apariencia exterior de un acto libre, voluntario, se acercaba mucho a una obligación. Para todos los efectos prácticos, cada regalo era una restitución por el regalo de un servicio recibido antes o una compensación por un daño cometido, o tenía la finalidad de provocar un regalo en contrapartida, a veces inmediatamente, a veces en fecha futura, no necesariamente expresada.

Por otra parte, la detallada descripción del banquete es señal del extrañamiento del narrador sobre el ordenamiento bárbaro de una costumbre conocida por él. 
En el siguiente fragmento, Jenofonte recuerda este banquete al que parece haber interpretado de acuerdo a su imaginario ateniense, o al menos, con más piedad que Seutes, pues le reprocha no cumplir con lo pactado. Dice el fragmento:

\section{7. - X.An.VII.7.46 - Diferencias II}

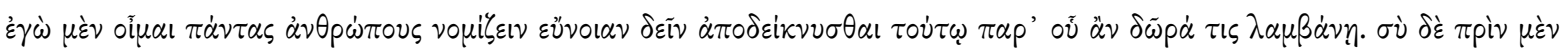

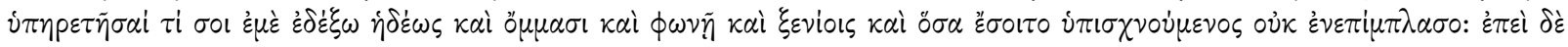

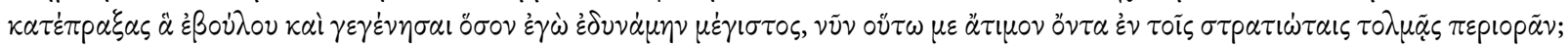

Yo, por un lado, creo que todos los hombres consideran necesario demostrar amabilidad ante ese del que cualquiera reciba regalos. Por otro, antes de servirte yo en cualquier cosa, tú me recibiste no solo con ojos y voz de buen grado, sino también con agasajos y no te cansabas al prometer cuantas cosas podían ser. Pero cuando lograste las que querías -y has llegado a ser cuan grandísimo yo era capaz - ¿Ahora de esta manera a mí, estando deshonrado para los soldados, osas mirar con recelo? ${ }^{13}$

Por $\xi \varepsilon v i o ı$ he preferido 'con agasajos' a 'con presentes de hospitalidad' -opción de otras traducciones-, pues refiere al banquete en sí y el uso en plural está especialmente vinculado a 'comida'; además, Seutes no ofreció ningún don particular a Jenofonte.

Por otra parte, poco antes, al valorar el estado previo de su vínculo, Jenofonte se refirió a Seutes como $\phi i \lambda o s$ $\psi v \chi \tilde{\eta} \varsigma$ (“amigo del alma”, VII.7.43), mientras que aquí, mostrando su desencanto, lo juzga inferior a $2 \nu \theta p \omega \pi \circ \varsigma$ (forma mucho menos respetuosa que ả $\nu \dot{\rho}$ ). Así, en su estimación sobre el deterioro de su relación pone de manifiesto lo que entraña el ser huésped para 'todos los hombres', para 'cualquiera': el ser mutuamente amables, amigos.

El octavo fragmento presenta la raíz de $\xi \dot{\varepsilon} v o \varsigma$ en dos ocasiones, una de ellas como verbo. En él Seutes dialoga con los embajadores laconios Cármino y Polinico, quienes querían el ejército griego para luchar contra Tisafernes, por entonces sátrapa en Lidia. Dice:

\section{8. - X.An.VII.6.3 - El banquete de Seutes II}

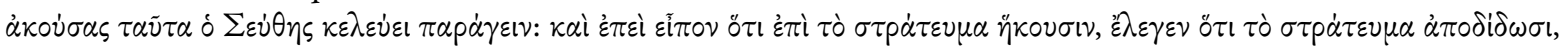

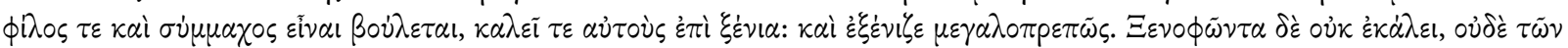
$\alpha \lambda \lambda \omega \nu \sigma \tau \rho \alpha \tau \eta \gamma \tilde{\omega} \nu$ ở $\dot{\varepsilon} \nu \alpha$.

Al escuchar estas cosas Seutes ordena traerlos discretamente. Y puesto que dijeron que llegan por el ejército, él decía que lo entrega, que desea ser su amigo y aliado y los invita a celebrar un banquete y recibe magníficamente con regalos hospitalarios. Pero no llamó a Jenofonte, ni a ninguno de los otros estrategos.

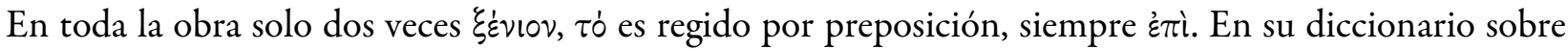
Anábasis White y Morgan (1896, p. 149) distinguen diferentes significados para cada pasaje: aquí entienden que se trata de la celebración de un asunto formal de estado, mientras que en el otro (VI.1.3) prefieren un sentido ligado a 'entretenimiento', pues allí los soldados brindan un banquete y entretienen a sus invitados con bailes, cantos y música. ${ }^{14}$

El verbo denominativo $\xi \varepsilon v i \zeta \omega$ contrasta con $\xi_{\varepsilon v o ́} \omega$, utilizado en el siguiente fragmento. El morfema -i $\zeta_{\omega}$ posee varios valores, entre ellos se destaca el valor causativo, pero además es frecuentemente utilizado con el sentido de 'celebrar una práctica religiosa', por ejemplo: $\alpha \phi p o \delta ı \sigma \dot{\alpha} \zeta \omega$ ("celebrar a Afrodita"), aquí: celebrar la unión hospitalaria.

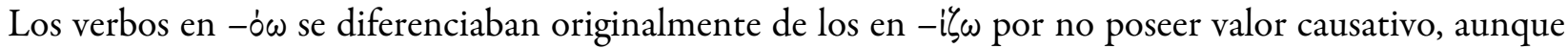
durante el período clásico lo adquieren. Sin embargo, el valor causativo es propio de la voz activa, y aquí se presenta en voz media. ${ }^{15}$ Dice el noveno fragmento:

\section{9. - X.An.VII.8.8 - Hospedarse}

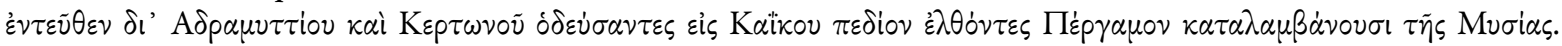

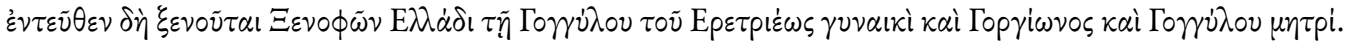


Desde allí a través de Adramitio y Citonio viajaron hacia la llanura de Caico. Tras llegar, ocuparon Pérgamo de Misia. Precisamente allí, Jenofonte se hospeda con Hélade, esposa de Góngilo, el eretrio, y madre de Gorgión y Góngilo.

Existen noticias sobre Góngilo en Tucídides (I.128.6) y en Cornelio Nepote (Pausanias, 2). Ambos cuentan que Pausanias, regente de Esparta, tras conquistar Bizancio se la entregó a Góngilo, el eretrio, para realizar negociaciones con el rey persa por medio suyo. En Helénicas III.1.6 Góngilo también es mencionado como "el único eretrio que fue desterrado por ser partidario de los medos". Góngilo debió ser un poderoso hombre de fama y sin duda se lo incluye y se señala el vínculo por ello. No parece adecuado en tal contexto interpretar que Jenofonte 'se hace hospedar con Hélade'.

Con las muestras décima y undécima se presentan aspectos idealizados de la xenía:

10. - X.An.I.3.3 - Clearco y Ciro

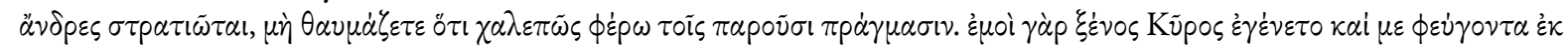

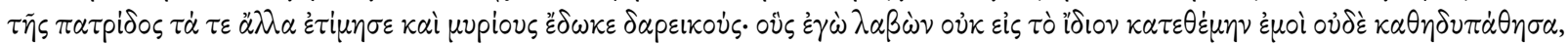

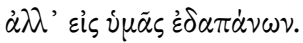

Hombres, soldados, no se asombren de que penosamente sufra por los problemas presentes pues conmigo Ciro llegó a estar unido por lazos de hospitalidad y a mí al estar exiliado de la patria me honró de varias formas y, en particular a mí me entregó diez mil daricos a los que tras haber tomado, yo no guardé para mí, ni derroché en lujos para mí, sino gastaba en ustedes. ${ }^{16}$

Este discurso se da en el contexto de un motín, el orador es Clearco. ${ }^{17}$ Para cesar la revuelta convoca a una asamblea ante la que llora, sorprendiendo a los soldados; luego sigue este discurso donde enfatiza patéticamente lo difícil de su situación: si respalda a los soldados traiciona a Ciro, su xénos, y si apoya a Ciro los traiciona a ellos. El vínculo de protección entre xénos no solía honrarse cuando uno de los huéspedes era desterrado, por lo tanto el haber honrado la relación es presentado como un gran gesto de Ciro. En su discurso Clearco continúa haciendo hincapié en la memoria que de él se tenga en la posteridad:

Si hago lo justo, en verdad no lo sé, pero os elegiré a vosotros y con vosotros sufriré lo que haga falta. Y nadie dirá nunca que yo, tras conducir a los griegos hacia los bárbaros, traicionando a los griegos escogí la amistad de los bárbaros, sino que, ya que no queréis obedecerme, yo seguiré con vosotros y sufriré lo que haga falta. Pues considero que vosotros sois mi patria, mis amigos y mis aliados, y con vosotros creo que puedo ser honrado dondequiera que esté; en cambio, estando falto de vosotros creo que no sería capaz ni de ayudar a un amigo ni de rechazar a un enemigo. Por tanto, tened esta opinión de que yo voy a dondequiera que vosotros vayáis. (X.An.I.3.5-6, trad. Varias, 1999)

En el fragmento undécimo el vínculo hospitalario entre Jenofonte y Próxeno es descripto como ancestral [äpxaĩos], ${ }^{18}$ es decir, heredado:

11. - X.An.III.1.4 - Jenofonte y Próxeno I

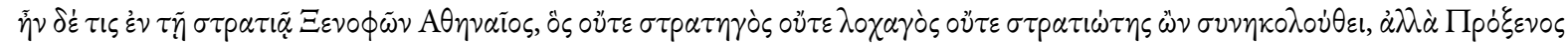

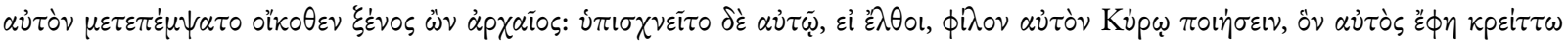

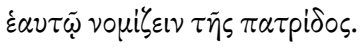

En el ejército había un tal Jenofonte, ateniense, que marchaba sin ser estratego ni capitán ni soldado, sino porque Próxeno, siendo su huésped ancestral, había enviado por él desde lejos de su casa y le prometía, si podía ir, hacerlo amigo de Ciro, lo cual él decía considerar para sí mejor que la tierra de sus antepasados.

Tradicionalmente se considera este fragmento la presentación formal de Jenofonte en el relato, aunque ya ha sido nombrado en I.8.15, II.4.15, 5.37, 40. El uso de $\tau$ เs lo introduce casualmente, como un individuo sin importancia. ${ }^{19}$

El juicio del beocio Próxeno sobre la patria es llamativo, pues es sabido el valor fundamental que la patria tenía para los antiguos. Por un lado, debe considerarse que acontecimientos como la Guerra del Peloponeso y la guerra civil entre demócratas y proespartanos, entre los que suele incluirse a Jenofonte, afectaron los lazos familiares y los preceptos religiosos. 
Por otro lado, quizá la explicitación del sujeto, a j̇òs, marca una diferencia entre Jenofonte y él. Además, si bien Jenofonte fue desterrado de Atenas, ${ }^{20}$ la patria mantiene un lugar central en el relato: en el anhelo de

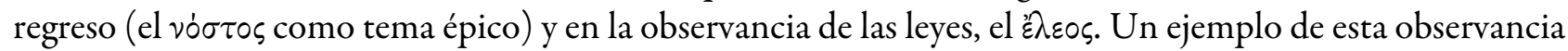
-entre muchos posibles- aparece en un diálogo entre Jenofonte y Euclides, un adivino, quien le recomienda hacer sacrificios "como en casa" a Zeus Miliquio ('acogedor de sacrificios expiatorios') pues Jenofonte se encuentra sin dinero y debe vender su caballo para regresar a Atenas:

Jenofonte respondió que no había hecho sacrificios a esta divinidad desde que estaba ausente de su patria [...] Al día siguiente, Jenofonte se acercó a Ofrinio para celebrar un sacrificio y un holocausto de lechones según la costumbre paterna $[\tau \tilde{\omega} \pi \alpha \tau p i \omega$ vó $\mu \omega]$ ], y las víctimas fueron propicias. Y en ese día llegaron Bión y Nausiclides para dar dinero al ejército, agasajaron a

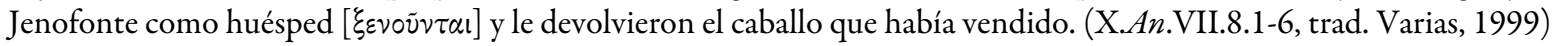

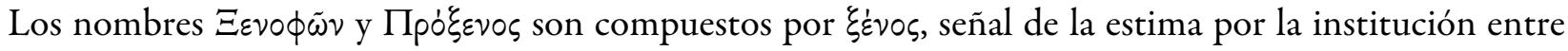
aristócratas, siendo el de Próxeno especialmente interesante por ser homófono al cargo con que se designaba a un representante de una ciudad en otra.

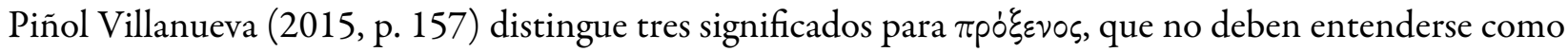
categorías excluyentes, sino como concreciones diferentes de una misma noción, según los usos y necesidades de cada ciudad. En el sentido más extendido $\pi$ pó $\xi \varepsilon v o s$ era un título concedido a un ciudadano de una determinada pólis al que la ciudad otorgante encargaba la acogida y protección de sus ciudadanos cuando allí

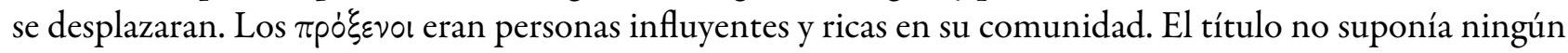
tipo de reconocimiento por parte de la propia pólis del beneficiario, solo de la pólis que lo había nombrado.

Paralelamente, en el ámbito jurídico, próxenos era utilizado como sinónimo de $\mu \dot{\alpha} p \tau \nu \varsigma$ ("testigo"); la similitud se debe a que el $\pi p o ́ \xi \xi v o \varsigma$ se desempeñaba como garante en acuerdos entre poblaciones vecinas. Por último, el término también pudo haber designado a un magistrado con competencia sobre extranjeros o un tipo de personal del santuario de Zeus Olímpico. Muchas inscripciones contienen el término, generalmente en plural. Una de ellas, por ejemplo, prescribe: "aquel de ambos pueblos que no se atenga a lo pactado, los próxenos y los adivinos lo excluyan del altar”. ${ }^{21}$

En el fragmento duodécimo aparece el verbo $\pi \rho \circ \xi \varepsilon v \dot{\varepsilon} \omega$, proveniente $\pi \rho \dot{\xi} \xi \varepsilon v \circ \varsigma$.

12. - X.An.VI.5.14 - $\Xi \varepsilon v \circ \phi \tilde{\omega} \nu \pi \rho \circ \xi \xi \nu \omega \nu$

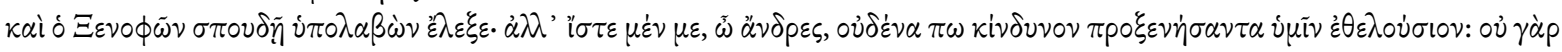

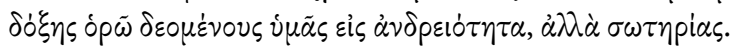

Pero Jenofonte tras interrumpir apresuradamente dijo: ¡Al contrario! Sepan, oh soldados, que yo hasta este momento ningún peligro les presenté voluntariamente, pues no los veo necesitando fama en valentía, sino una salvación.

El significado del verbo cobra sentido al pensar en las responsabilidades de un próxeno para con un extranjero: procurarle hospedaje, proveerle seguridad, mediar entre él y los miembros de la comunidad local,

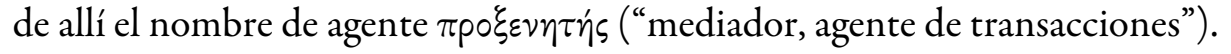

El fragmento decimotercero muestra la honra que a Próxeno hace Jenofonte en Delos, a causa de haber sido xénos, al realizar una inscripción en el tesoro ateniense: ${ }^{22}$

13. - X.An.V.3.5 - Jenofonte y Próxeno II

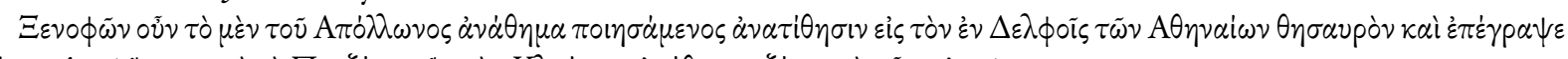

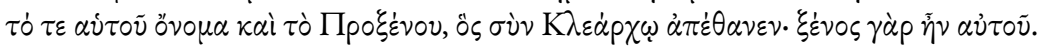

Así pues, Jenofonte habiendo hecho por su cuenta y en su interés una ofrenda a Apolo, la coloca dentro del tesoro de los atenienses en Delfos e hizo una inscripción tanto de su nombre como en particular el de Próxeno, quien junto a Clearco murió, pues era amigo de él.

El $\mu \dot{\varepsilon} v$ solitarium cobra sentido en el contexto de la frase, pues previamente fue descripto como se repartió un botín, resaltando el destino piadoso que Jenofonte le dio a su parte frente a lo que hicieron otros. Además, la voz media del participio $\pi \circ \eta \sigma \dot{\alpha} \mu \varepsilon v o s$ aporta el interés propio de la acción. 


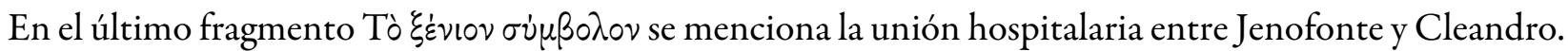

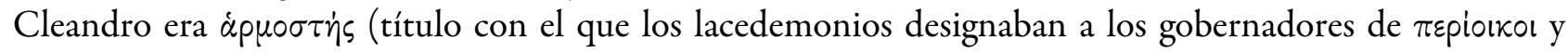
colonias) y quería dirigir el ejército en su retorno a la Grecia continental, pero una curiosa situación ocurre en el contexto: habiendo realizado sacrificios para la marcha los auspicios no le son buenos, por lo que finalmente no conduce al ejército y marchan separados. Al despedirse, les promete a los generales que al reencontrarse los espartanos los recibirán de la forma más hermosa posible $\left[\delta \varepsilon \xi \dot{\partial} \mu \varepsilon \theta \alpha \dot{\omega} \zeta \ddot{\alpha} \nu \delta \nu \nu \dot{\omega} \mu \varepsilon \theta \alpha \kappa \dot{\alpha} \lambda \lambda \_\tau \alpha\right]$, por ello los soldados acuerdan regalarle ganado del "fondo común", lo cual Cleandro acepta y a su vez devuelve. Dice el fragmento:

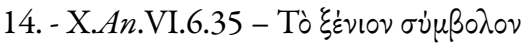

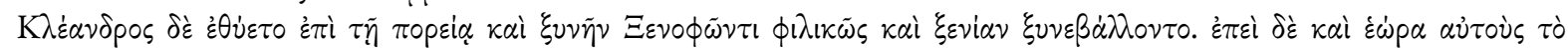

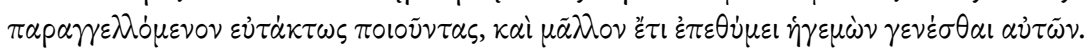

Cleandro hacía sacrificios en busca de auspicios sobre el viaje y acompañaba a Jenofonte amistosamente y se reunían como huéspedes. Y puesto que por un lado veía a los haciendo disciplinadamente lo mandado, por otro deseaba aún más llegar a ser su jefe.

Además, este pasaje presenta la particularidad de utilizar arcaísmos para nombrar la acción de 'unión hospitalaria', el verbo utilizado $\xi \nu \mu \beta \dot{\alpha} \lambda \lambda \omega$ da origen al sustantivo $\sigma \dot{\nu} \mu \beta \circ \lambda \circ \nu,{ }^{23}$ objeto de singular importancia

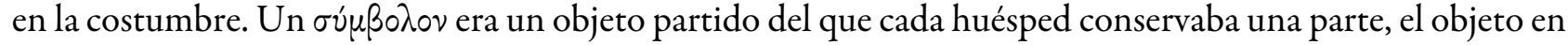
sí no tenía valor, solían ser trozos de cerámica o monedas partidas; pero su calce probaba el vínculo y así el objeto servía como salvoconducto para descendientes u otros miembros de la familia.

No se puede asegurar la preferencia del arcaísmo $\xi \nu \mu \beta \dot{\alpha} \lambda \lambda \omega$ sobre $\sigma \nu \mu \beta \dot{\alpha} \lambda \omega \omega$ con relación a esta práctica ritual, puesto que ambas formas fluctúan, pero según Adrados es posible atribuir a la forma arcaica $\xi \dot{v}$ el deseo de mantener cierta dignidad. ${ }^{24}$

Algunos autores dicen que diversos rituales sellaban este pacto. Por ejemplo, Iriarte indica que el huéspedanfitrión debía pronunciar la frase "os convierto en mi huésped", luego el huésped-invitado debía aceptar compartir los alimentos de la mesa, luego se ofrecían dones y contra-dones, y finalmente al despedirse los huéspedes conservaban un sýmbolon. En cambio, para Konstan "no hay una ceremonia prescripta para establecer xénia [...] no hay evidencia que la amistad entre extranjeros fuera solemnemente sellada con formalidades rituales". 25

\section{Conclusión}

El significado 'extranjero' no es la única acepción de $\zeta \dot{\varepsilon} v o \varsigma$ y no es siempre apropiada en Anábasis, pues en muchas ocasiones es utilizado con su sentido original de 'ser unido en hospitalidad', 'huésped', o incluso 'amigo', y también ocasionalmente es usado para nombrar a mercenarios. Además, el hecho de que en la práctica ceremonial del vincularse hospitalariamente el compartir comida e intercambiar regalos constituyesen pasos protocolares, provoca que en ocasiones el uso neutro plural $\xi \dot{\varepsilon} v 1 \alpha$ refiera a 'comida' o 'regalos, dones'.

El uso como 'mercenario' constituía un eufemismo debido a que el ser contratado y recibir un salario era contrario a la idea del hombre libre y autárquico. Muestras de esta mala consideración son el cambio lingüístico dado sobre el referente 'mercenario', la reescritura desambiguadora de Diodoro mencionada por Trundle y el hecho que en Anábasis Jenofonte utilizara $\mu \sigma \theta o ́ \phi o p o s ~ ' c o n t r a t a d o s$ ' o Kúpeıs 'cireanos' para designar a enemigos o desertores, mientras que opta por $\xi \dot{\varepsilon} v o \mathrm{u} u$ otros términos para sus compañeros.

Este eufemismo cobraba sentido por dos vías, por un lado, metonímicamente del hecho que la mayoría de los mercenarios eran efectivamente extranjeros; por otro lado, implicando el vínculo de defensa mutua de la antigua y honorable costumbre de la $\xi \dot{\varepsilon} v i \alpha$. La buena estima sobre esta costumbre se demuestra en su uso como nombre propio entre aristócratas (Jenofonte, Próxeno, Jenias), la valoración que realiza Clearco de su 
vínculo con Ciro en I.3.3, o el hecho que en su paso por Delos Jenofonte haya incluido en su inscripción el nombre de su amigo Próxeno, su xénos ancestral.

Además, este último sentido sobre el término 乡̇ंvos permite ver un mecanismo de cohesión social, pues la primitiva vinculación como huéspedes ligada a la religión doméstica amplió con el tiempo su alcance, reformulándose en la religión civil y siendo posiblemente motivo del nombre $\xi \varepsilon v i k o ́ v$, en el sentido que era un grupo de individuos que había sido aceptado en algún grado por una pólis (entendiendo a esta como una comunidad religiosamente unida) y dejando de ser, por lo tanto, extranjeros para ella. Este sentido actúa

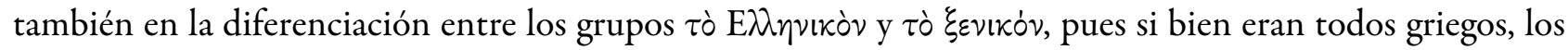
primeros mantenían el vínculo de pertenencia con su comunidad de origen, mientras que los segundos habían sido integrados por ciudades persas.

Finalmente, sobre esto último no dejan de ser notables las palabras con que Próxeno invitó a Jenofonte: aquello de que consideraba mejor ser amigo de Ciro que la tierra de sus antepasados, pues muestra un deseo de emigrar y una identidad en crisis posiblemente causados por los efectos sobre la población de la Guerra del Peloponeso y el conflicto entre demócratas y proespartanos.

\section{ReFERENCIAS}

Adrados, F. (1999). Historia de la lengua griega. Madrid: Gredos.

Bailly, M. A. (1935). Dictionnaire Grec Français. Paris: Hachette.

Berruecos Frank, B. (2018). Poesía arcaica griega (Siglos VII-V a. C.). México: Universidad Nacional Autónoma de México.

Burckhardt, J. (1971). Historia de la cultura griega. Barcelona: Iberia.

Chantraine, P. (1968). Dictionnaire étymologique de la langue grecque. Historia des mots. Paris: Klincksieck.

Cirac Estopañan, S. (1957). Manual de gramática histórica griega. Barcelona: CSIC.

Coulanges, Fustel de (1996). La ciudad antigua. Bogotá: Edaf.

Dindorf, L. A. (1855). Xenophontis Expeditio Cyri. Oxford: Kessinger.

Dubreuil, R. (2016). Theatrica and Political Action in Plutarch's Parallel Lives. Edimburgo: The University of Edinburgh.

Finley, M. (1954). El mundo de Odiseo. México: Fondo de Cultura Económica.

Finley, M. (1984). La Grecia Antigua. Barcelona: Crítica.

Goodwin, W. W. \& White, J. W. (1896). The first four books of Xenophon's Anabasis. Boston: Ginn and Co.

Gutiñas Tuñón, O. (1994). Jenofonte. Helénicas. Madrid: Gredos.

Harper, W. \& Wallace, J. (1921). Xenophon's Anabasis seven books. Nueva York: American Book.

Hoffman, O.; Debrunner, A.; Scherer, A. (1973). Historia de la lengua griega. Madrid: Gredos.

Iriarte, A. (2007). La institución de la Xenía: pactos y acogidas en la antigua Grecia. Gerión, Extra, 197-206.

Konstan, D. (1997). Friendship in the classical world. Cambridge-Nueva York: Cambridge University Press.

Marchant, E. C. (1904). Jenofonte. Expeditio Cyri. Oxford: Oxford University Press.

Masqueray, P. (1964). Jenofonte. Anabase. París: Universites de France-Association Guillaume Bude.

Mitsos, M. T. \& Vanderpool, E. (1950). Inscriptions from Attica y Addendum. Hesperia, 19: 25-30 y 391.

Piñol Villanueva, A. (2015). El extranjero en la Grecia arcaica: acceso a la tierra y a la justicia. Barcelona: Universitat Autònoma de Barcelona.

Segura Moreno, M. (1985). Cornelio Nepote. Vidas. Madrid: Gredos.

Taber Murray, A. (1914). The Anabasis of Xenophon. Chicago: Foresman and Co.

Trundle, M. F. (1996). The Classical Greek Mercenary and his Relationship to the Polis. Hamilton : McMaster University. 
Varias García, C. (1999). Jenofonte. Anábasis. Madrid: Cátedra.

White, W. \& Morgan, M. (1896). Illustrated dictionary to Xenophon's Anabasis. Boston: Ginn and Co.

\section{Notas}

1 Las traducciones son propias, salvo que se indique lo contrario. El texto griego sigue la edición de Marchant.

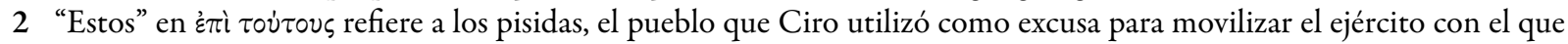
marchó hacia Babilonia. En cuanto al nombre Jenias, formado con la raíz de $\xi \dot{\varepsilon} v o \varsigma$, cabe señalar que los editores Dindorf y Masqueray prefieren la variante $\Xi \varepsilon v \nu i \alpha$ de los manuscritos ACD, no así Hude y Marchant que siguen a V y otros. Dice Chantraine (1968, p. 764) que las variantes geminadas podrían ser expresivas. La secuencia - $\tau \tau-$ en $\phi v \lambda \dot{\alpha} \tau \tau \varepsilon เ \nu$ es marca de aticismo; según Adrados, el ático la tomó del beocio y con ella reemplazó - $\sigma \sigma-$, pero es rara en prosa ática pues aticismos como - $\tau \tau-\mathrm{y}-\rho p$ - no tenían prestigio y eran vistos como provincianismos.

3 Ver Burckhardt, 1971, p. 60; Trundle, 1996, p. 77.

4 El término pater no refiere necesariamente al padre, sino que designa al líder de la religión doméstica; como padre era utilizado el término $\gamma \varepsilon v \dot{\varepsilon} \tau \eta \xi$. Esta diferencia se percibe, por ejemplo, en que la palabra que más cercana a 'extranjero' en

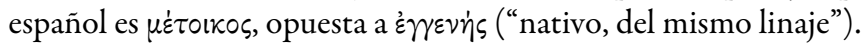

5 Según Varias, Aristipo era miembro de los Alévadas (1999, p. 28).

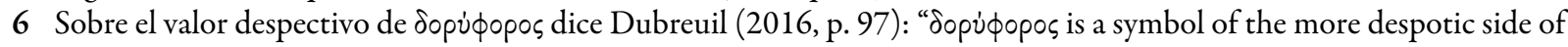
monarchy, especially Macedonian monarchy, it is also the term used in theatrical terminology to designate the mute extra on stage [...] These figures were part of the imagery associated in tragedy with despotic figures. For instance, Aegisthus, King Agamemnon's half-brother [...] is repeatedly associated with these figures. Aeschylus' Aegisthus is expected to arrive on stage with spearmen accompanying him (Aesch. Lib. 769), while Euripides' usurper is depicted as protecting himself against Orestes, Agamemnon's son and his future killer, with a bodyguard (Eur. El. 616)".

7 Diehl 40. Según Berruecos Frank (2018, pp. CVI-CVII), si bien no se conoce el contexto del verso "parece referirse a un suceso en una batalla, en la cual la participación de la persona loquens podía equipararse a la de los mercenarios carios

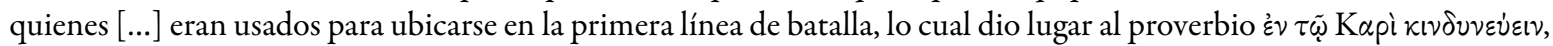
referido al atrevimiento y al riesgo tomados a costa de otros".

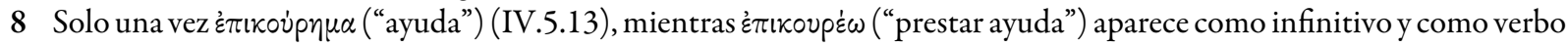
conjugado (V.8.21 y V.8.25).

9 X.Hel.II.4.31, IV.2.5, 4.9, 14, 8.35, V.4.45, 54, VI.1.5, 2.5, 16, 18, 4.9, 28, 5.12, 15, 29, VII.1.12, 2.11, 21, 4.6.

10 Esto mismo sucede en Helénicas, donde $\xi \dot{\varepsilon} v \circ \varsigma$ es usado para referir 'mercenario' pocas veces, y la mayoría de ellas se indica que son contratados (I.4.43, V.2.38, VI.1.5).

11 En X.An.V.5.1-3 se halla un ejemplo digno de mención: el ejército se encuentra en el territorio de los tibarenos, quienes envían provisiones como regalos $[\tau \dot{\alpha} \xi \dot{\xi} v i \alpha]$ al ejército, pero su aceptación no fue inmediata, pues los generales querían saquear el lugar. Antes de rechazar la oferta se realizaron sacrificios y los adivinos dijeron que los dioses no admitían la guerra, por lo que entonces sí se aceptaron los regalos de hospitalidad.

12 Un intercambio de este tipo se comenta sobre el fragmento X.An.VI.6.35.

13 La situación de deshonra de Jenofonte se debe a que cuando Seutes no necesita más a los mercenarios griegos les escatima la paga; en consecuencia los soldados se quejan con Jenofonte y él se queja con Seutes, quien sin éxito intenta reemplazarlo como líder del ejército. Simultáneamente llegan emisarios laconios en busca del ejército, lo que Seutes aprovecha como se ve en octavo fragmento.

14 En ambas ocasiones los manuscritos varían en el caso del término, la mayoría presenta dativo; solo A y K, acusativo. De los editores consultados solo Clark prefiere el dativo. La diferencia de caso construye distintos sentidos: en dativo puede interpretarse como circunstancial temporal o modal ("invitó como huéspedes"), mientras que en acusativo presenta valor de finalidad, y con tal sentido he traducido, pues entiendo que la invitación se hace para sellar el acuerdo.

15 Ver Cirac Estopañan, 1957, pp. 11-12 y 16-17.

16 Hay diferentes interpretaciones sobre la construcción de ac. $\alpha^{2} \lambda \alpha \alpha+\tau \varepsilon$, $\kappa \alpha$ ì. En mi traducción entiendo que $\tau \dot{\alpha} \tau \varepsilon \dot{\alpha} \lambda \lambda \alpha$

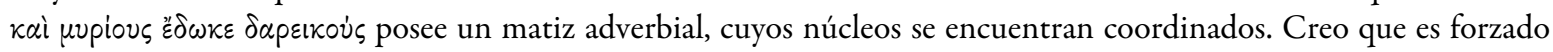
interpretar $\tau \dot{\alpha} \dot{\alpha} \lambda \lambda \alpha$ como OD, refiriendo a regalos pasados implícitos por la costumbre hospitalaria: $\dot{\varepsilon} \tau \dot{i} \mu \eta \sigma \varepsilon \mu \varepsilon \tau \dot{\alpha} \tau \varepsilon \dot{\alpha} \lambda \lambda \alpha$ ("respetó a mí y a las otras cosas"). Por el mismo motivo descarto un ac. de relación "me honró tanto como las otras cosas / en la medida de los regalos pasados”. Por otras interpretaciones ver Goodwin y White (1896, p. 173), Taber Murray (1914, p. 30), Harper y Wallace (1921, p. 83).

17 Sobre Clearco ver Burckhardt, 1971, pp. 52-54.

18 He preferido traducir ảpxaĩos como 'ancestral' pues con tal sentido califica a linajes o costumbres (resp. I.9.1, VII.3.28), mientras que como atributo de un objeto es usado como "viejo, antiguo" (IV.5.14). 
19 Este mismo recurso es utilizado para introducir anécdotas, como con Gnesipo (VII.3.28) o Epistenes de Olinto (VII.4.7); pero también para presentar personajes relevantes, como Heraclides de Maronea (VII.3.16) con quien Jenofonte rivaliza en su paso por Tracia.

20 Entre las posibles causas se encuentra el participar de la expedición de Ciro o el luchar al mando de los kípeios ("cireanos”) contra Atenas en Coronea.

21 IvO 10=Minon 14. Trad. Villanueva.

22 En 1948 fue hallada frente a la iglesia de Panagia, Merenda, al sureste de Markopoulo, sitio del antiguo demo Myrrhinous, una piedra que puede contener una parte de la inscripción hecha por Jenofonte, pues aparece su nombre (aunque el nombre $\Xi \varepsilon \nu \circ \phi \tilde{\omega} \nu$ era muy común). Según los arqueólogos Mitsos y Vanderpool es posible que la piedra no perteneciera al lugar, pues no hay testimonios de adoración a Apolo Pitio en la zona, aunque es sí es mencionado sin epíteto en un juramento preservado en el sitio. La piedra podría haber llegado al lugar desde el puerto cercano de Prasiai, pues era costumbre navegar a Delos desde allí. Desde 1949 esta piedra pertenece a la colección del Museo Epigráfico de Atenas (EM 13.120). La inscripción se halla bajo varios grafitis, la piedra está partida y cavada en uno de sus lados para sostener el arco de una ventana de iglesia. La restauración de la primera línea fue sugerida por Werner Peek; la segunda línea se tomó como idéntica a la inscripción de Peisitratos, el joven, en el altar de Pitia (IG I2, 761). Dice:

En 1948 fue hallada frente a la iglesia de Panagia, Merenda, al sureste de Markopoulo, sitio del antiguo demo Myrrhinous, una piedra que puede contener una parte de la inscripción hecha por Jenofonte, pues aparece su nombre (aunque el nombre $\Xi \varepsilon \nu \circ \phi \tilde{\omega} \nu$ era muy común). Según los arqueólogos Mitsos y Vanderpool es posible que la piedra no perteneciera al lugar, pues no hay testimonios de adoración a Apolo Pitio en la zona, aunque es sí es mencionado sin epíteto en un juramento preservado en el sitio. La piedra podría haber llegado al lugar desde el puerto cercano de Prasiai, pues era costumbre navegar a Delos desde allí. Desde 1949 esta piedra pertenece a la colección del Museo Epigráfico de Atenas (EM 13.120). La inscripción se halla bajo varios grafitis, la piedra está partida y cavada en uno de sus lados para sostener el arco de una ventana de iglesia. La restauración de la primera línea fue sugerida por Werner Peek; la segunda línea se tomó como idéntica a la inscripción de Peisitratos, el joven, en el altar de Pitia (IG I2, 761). Dice:

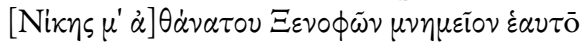

de mi victoria inmortal, Jenofonte, memoria por mí mismo

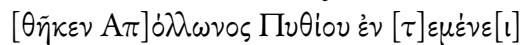
ofrendó a Apolo Pitio en este lugar.

23 En cuanto a $\sigma \dot{\nu} \mu \beta 0 \lambda$ ov como derivado de $\sigma \nu \mu \beta \dot{\alpha} \lambda \omega \omega$ ver Bailly, 1919, pp. 1821-1822. Marchant y Masqueray prefieren

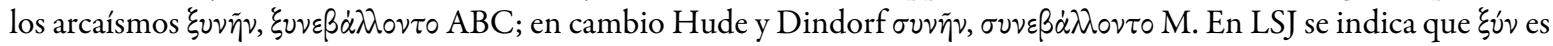
infrec. en Homero, pero que no es raro en compuestos de inscripciones anteriores al s. $\mathrm{V}$ a. C. incluso sin ser requisito métrico, mientras que $\sigma u ́ v$ es posterior. Por lo tanto, לúv es considerado aticismo o arcaísmo. Ver Adrados, 1999, p. 50; Hoffman, 1973, pp. 309-310.

24 Ver Adrados, 1999, p. 132

25 Iriarte, 2007: 200. Konstan, 1997, p. 36.

\section{BY-NC-SA}

